\title{
Title: Archaeological assessment reveals Earth's early transformation through land use
}

\author{
Authors: ARCHAEOGLOBE Project [Stephens et al.]
}

\begin{abstract}
Environmentally transformative human use of land accelerated with the emergence of agriculture, but the extent, trajectory, and implications of these early changes are not well understood. An empirical global assessment of land use from 10,000 BP to $1850 \mathrm{CE}$ reveals a planet largely transformed by hunter-gatherers, farmers and pastoralists by 3,000 years ago, significantly earlier than land-use reconstructions commonly used by Earth scientists. Synthesis of knowledge contributed by over 250 archaeologists highlighted gaps in archaeological expertise and data quality, which peaked at $2000 \mathrm{BP}$ and in traditionally studied and wealthier regions. Archaeological reconstruction of global land-use history illuminates the deep roots of Earth's transformation and challenges the emerging Anthropocene paradigm that large-scale anthropogenic global environmental change is mostly a recent phenomenon.
\end{abstract}

One Sentence Summary: A map of synthesized archaeological knowledge on land use reveals a planet largely transformed by hunter-gatherers, farmers and pastoralists by 3,000 years ago.

\section{Main Text:}

Human societies have transformed and managed landscapes for thousands of years, altering global patterns of biodiversity, ecosystem functioning, and climate (1-6). Despite increasing interest in the early global environmental changes caused by human activities, from changes in fire regimes and wild animal and plant populations by hunter-gatherers to increasingly intensive forms of agriculture, the global extent, intensity, temporal trajectory, and environmental consequences of Earth's transformation through human land use remain poorly understood outside the archaeological community (7-9).

Human transformation of environments around the world began with late-Pleistocene hunting and gathering societies and increased throughout the most recent interglacial interval with the emergence of agriculture and urbanized societies. Agricultural land use is implicated in anthropogenic global environmental changes, ranging from greenhouse gas emissions and climate change $(5,6,10)$ to widespread deforestation, soil erosion, and altered fire regimes, as well as species introductions, invasions, and extinctions $(4,8,11)$. Such changes are evident even in tropical rainforests and savanna environments long considered pristine $(12,13)$. Yet existing models of long-term changes in global land use $(5,14,15)$ differ substantially in their representation of these early transformations $(8,16)$, largely owing to limited incorporation of disparate empirical data from archaeology and palaeoecology $(17,18)$. As a result, global models and assessments of early anthropogenic influence on climate, habitats, biodiversity and other environmental changes remain poorly characterized $(4,10,18,19)$.

Efforts to map land-cover change over the past 10,000 years from pollen data have increased during the last decade and high quality regional reconstructions are now available for Europe and 
the Northern Hemisphere (20-24). However, global reconstructions that combine both land-use and land-cover change using a range of data sources are rare $(18,25)$ and have difficulty incorporating environmental data from archaeological sites (26). Here we present a global assessment of archaeological expert knowledge on land use from 10,000 BP to $1850 \mathrm{CE}$, showing that existing global reconstructions underestimate the impact of early human land use on Earth's current ecology.

\section{A global synthesis of archaeological knowledge}

Archaeologists often study human alterations of environments, but most studies are qualitative or have a local or specialized topical focus (e.g., (27-33)). To assess and integrate archaeological knowledge towards synthesis at a global scale, the ArchaeoGLOBE project used a crowdsourcing approach $(34,35)$. Archaeologists with land-use expertise were invited to contribute to a detailed questionnaire describing levels of land-use knowledge at ten time intervals across 146 regional analytical units covering all continents except Antarctica. Contributors selected individual regions where they had expertise; 255 individual archaeologists completed a total of 711 regional questionnaires, resulting in complete, though uneven, global coverage (Fig. 1; Table S1). The result is an expert based meta-analysis that uses semi-subjective (ranked) survey data to generate regional assessments of land use over time.

Regional-scale archaeological knowledge contributions were sufficient to assess land-use changes in all 146 regions between 10,000 BP and 1850 CE (Figs. 1 and 2). Overall, self-reported regional land-use expertise increased linearly from 10,000 BP, peaked at 2,000 BP and dropped off sharply thereafter (Fig. 2B), reflecting the decreasing emphasis on environmental archaeological methods in time periods with more abundant material remains and/or historical records. Quality of archaeological data pertaining to past land use (Fig. 2C), determined by the pervasiveness of archaeological surveys as well as floral and faunal analyses in each region, followed a similar trend to that for expertise, although the peak was somewhat later, more pronounced, and the drop-off less severe. 
A
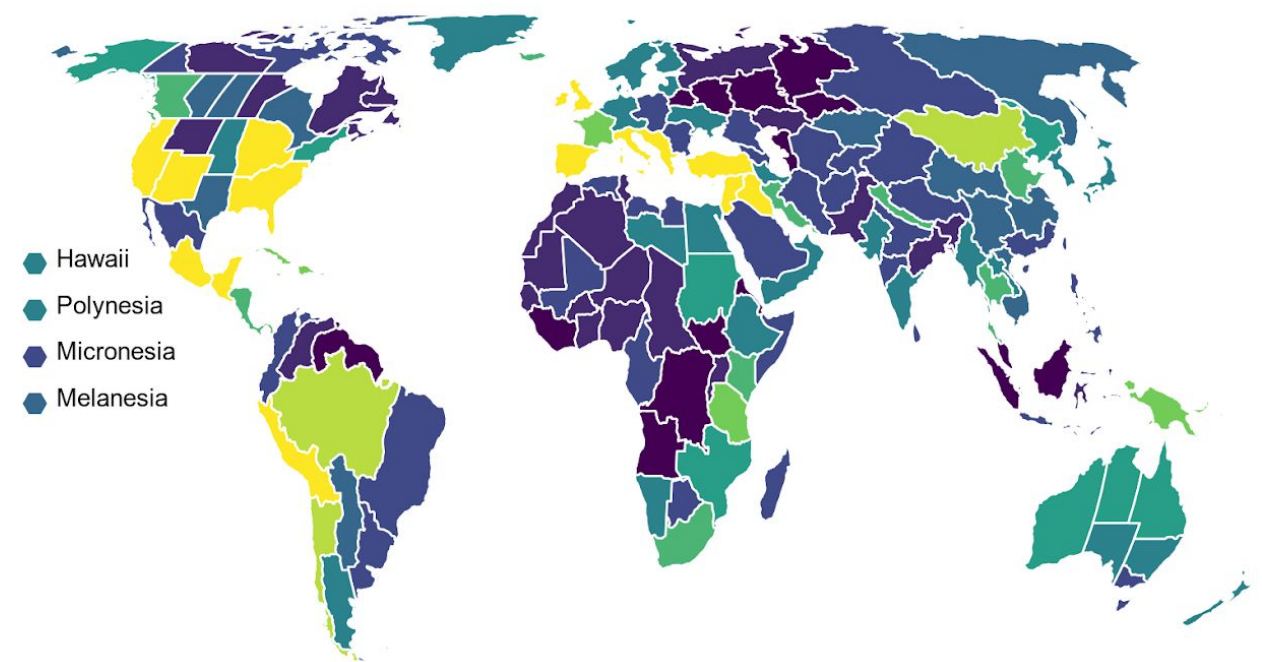

Contributors
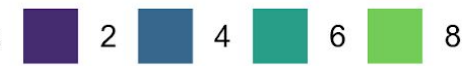

8 $10+$

B

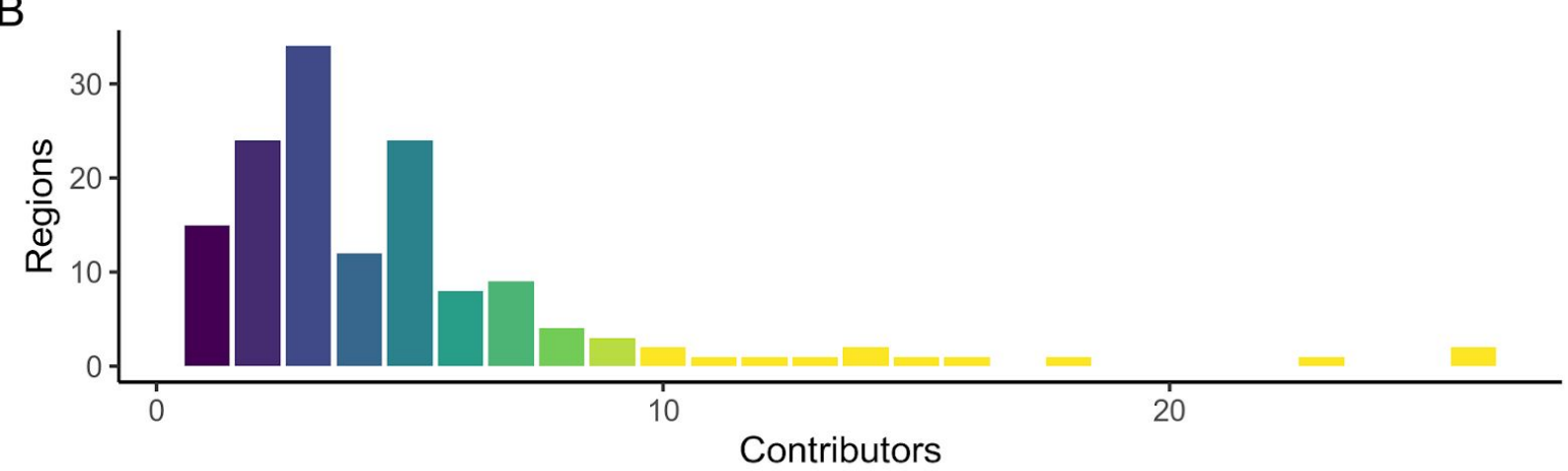

Fig. 1: Archaeological knowledge contributions. A) Geographic distribution of knowledge contributions across 146 regions. Four island regions at left are aggregated into indicator panels with exaggerated areas. Eckert IV projection. B) Histogram showing the distribution of contributions across regions, $\mathrm{n}=711$.

Global trends in expertise and data quality, and in published excavations, were heterogeneous across the globe, with consistently higher expertise and data quality across time in regions including, but not limited to, sections of Southwest Asia, Europe, Northern China, Australia, and North America, almost certainly reflecting a greater intensity of archaeological research in these areas. Other areas evidenced relatively low expertise among survey respondents and data quality until the most recent periods; especially parts of Africa, Southeast Asia, and South America. 
A

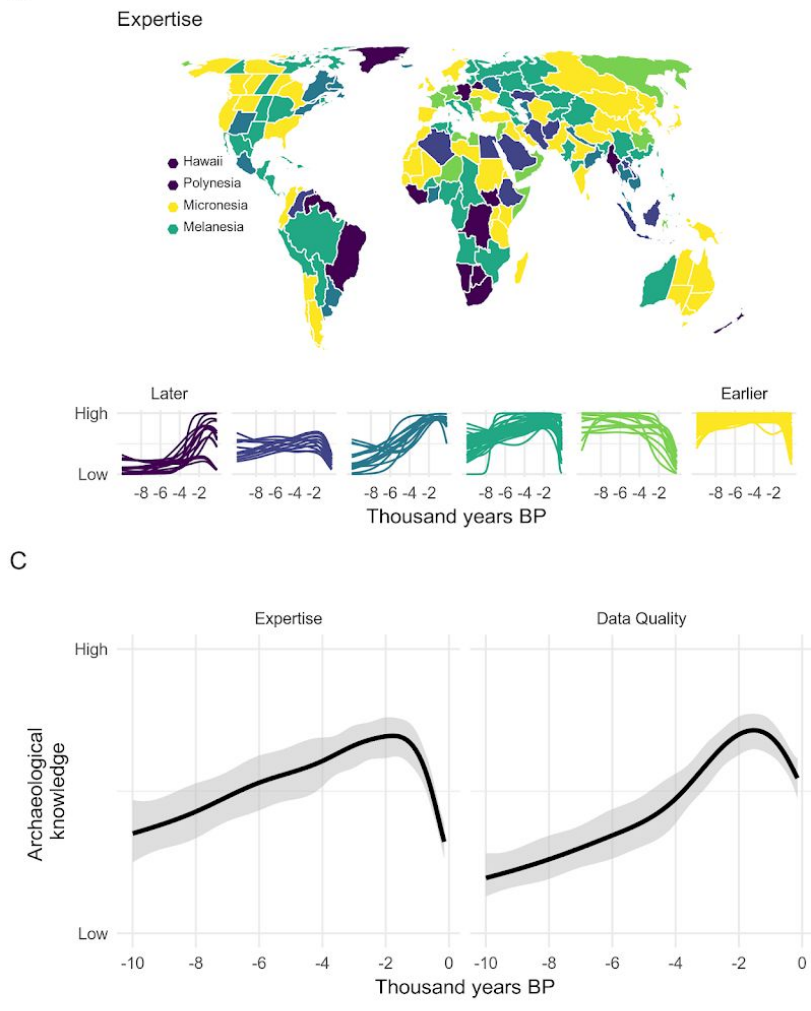

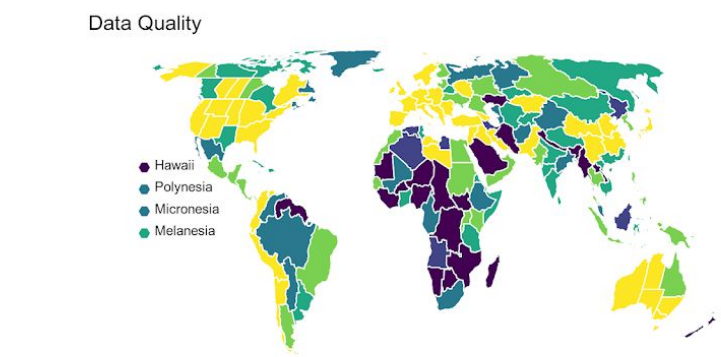

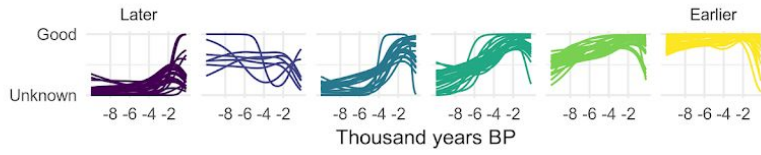

D

Published Excavations

Fig. 2: Archaeological expertise, data quality, and published excavations. A) Regional trends in land-use expertise estimated using a generalized additive mixed model, grouped according to a k-means clustering algorithm to show regions with similar temporal trends. B) Regional trends in data quality. C) Global trends in expertise and data quality with 95\% confidence intervals. D) Estimated number of published excavations per region.

\section{Global patterns of regional land-use change}

In 120 regions ( $82 \%$ of all regions, $88 \%$ of inhabited regions at $10,000 \mathrm{BP}$ ), foraging (practices of foraging, hunting, gathering and fishing) was common (practiced across $1 \%$ to $20 \%$ of land in region) or widespread (practiced across more than $20 \%$ of region) at $10,000 \mathrm{BP}$, and declined thereafter (Figs. 3A \& 4B). Foraging was less than widespread in $40 \%$ of all regions by 8,000 $\mathrm{BP}$, a decline that expanded to $63 \%$ of regions by $3,000 \mathrm{BP}$. By $1850 \mathrm{CE}, 73 \%$ of regions were assessed with less than widespread foraging, with $51 \%$ at the minimal (practiced across $<1 \%$ of land in region) or none prevalence levels.

Regional trends of foraging (Figs. 4B \& S6D), reveal early declines from 10,000-6,000 BP in Southwest Asia, with other regions exhibiting declines in foraging lifeways either gradually, beginning circa 4,000 BP, or with hardly any declines at all until after 3,000 BP. This pattern is congruent with recent global assessments indicating that the majority of domesticated species appeared in the interval from 8,000-4,000 BP, with a smaller number in earlier intervals (28). 
A

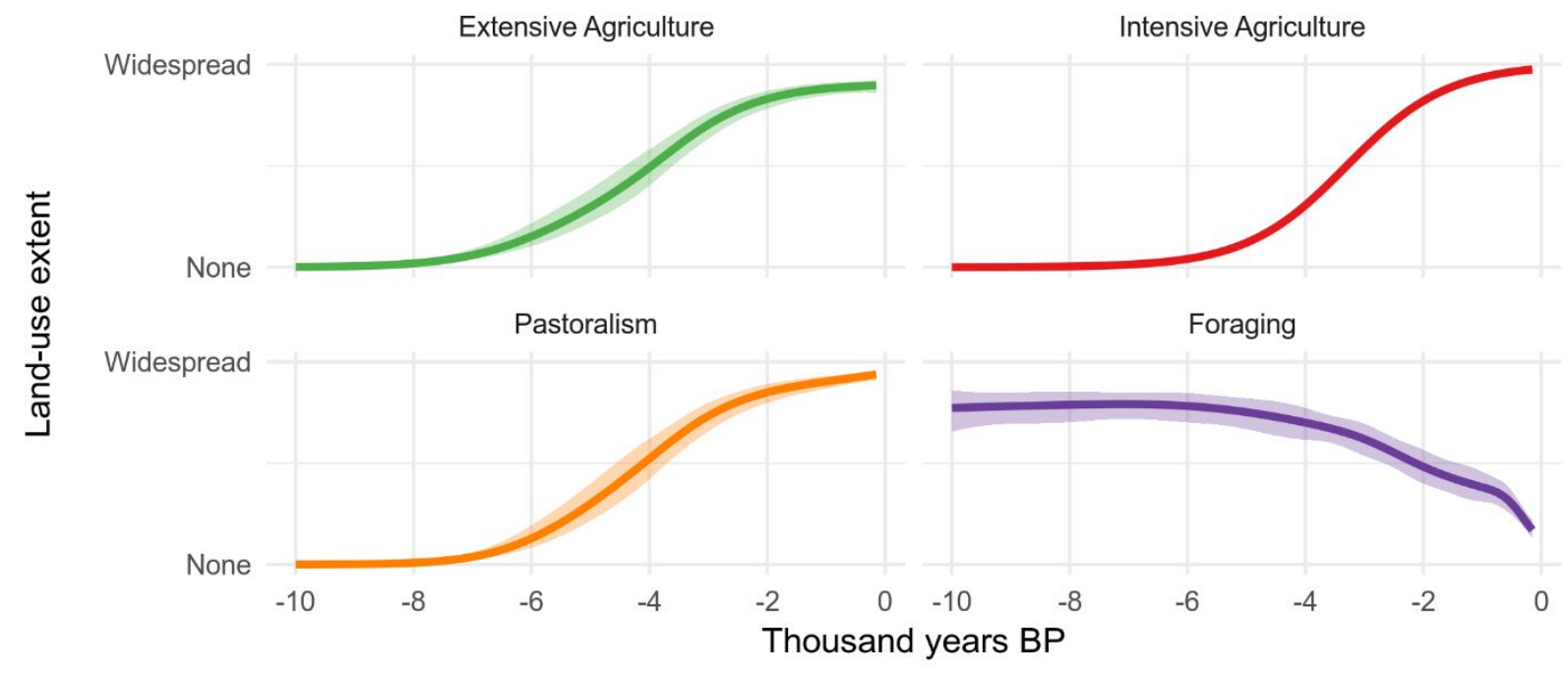

B

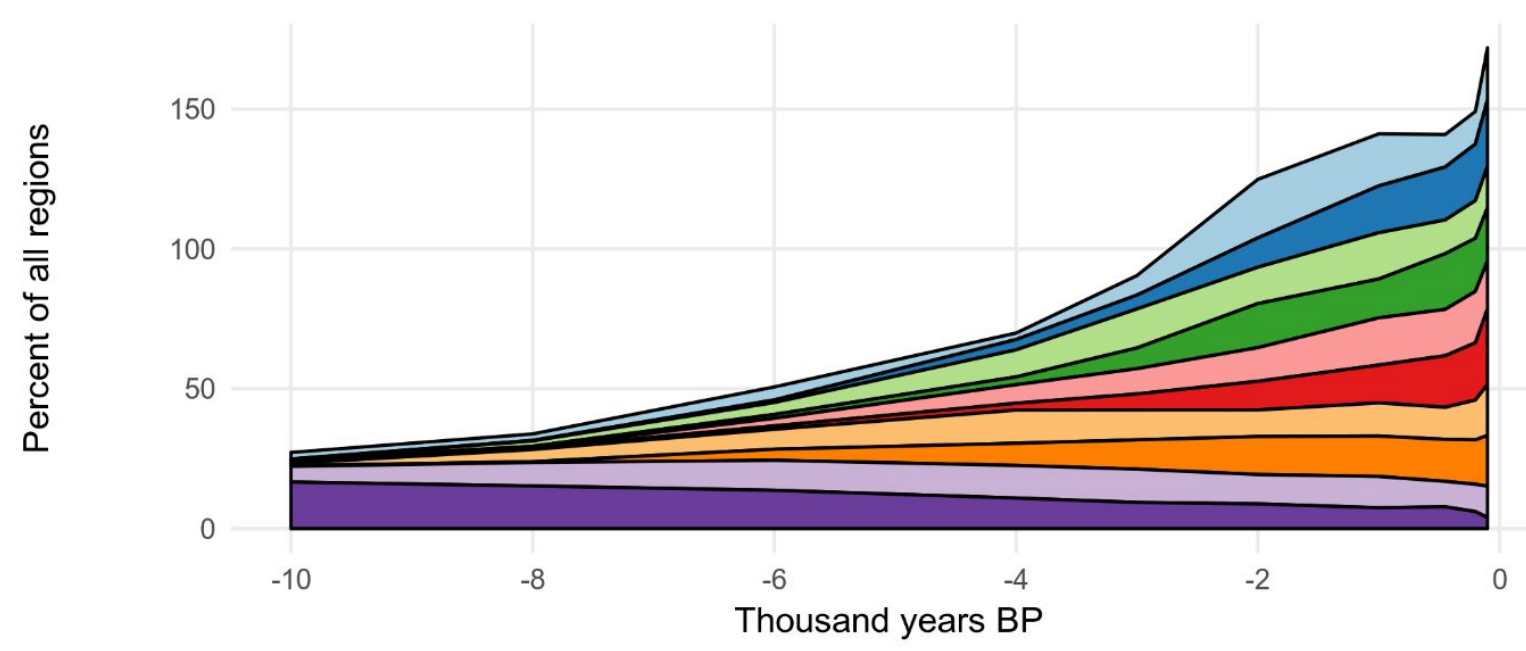

Urban Centers Split $\quad \square$ Urban Centers Present

Extensive Agriculture Common $\square$ Extensive Agriculture Widespread

Intensive Agriculture Common $\square$ Intensive Agriculture Widespread

Pastoralism Common $\quad \square$ Pastoralism Widespread

Foraging Common $\square$ Foraging Widespread

Fig. 3: Summary of global land-use trends. A) Generalized additive mixed model trends for the extent of each land-use type across all regions, with $95 \%$ confidence intervals. B) Cumulative summary of regions per land-use category based on consensus assessments (Common $>1 \%$ to $20 \%$ regional land area; Widespread $>20 \%$ regional land area), with presence or absence of urban centers. Categories are non-exclusive, resulting in plot values $>100 \%$ of all regions. 


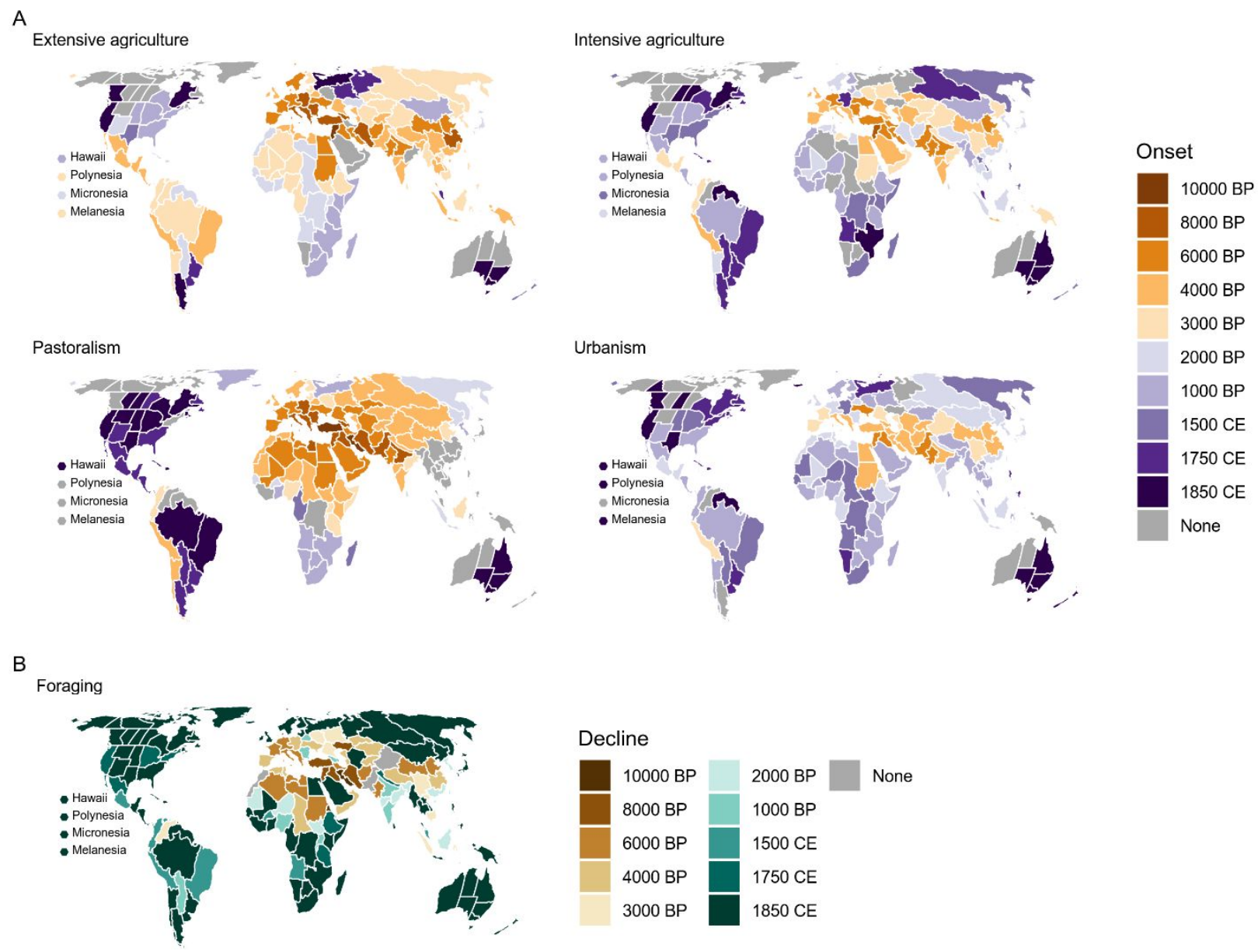

Fig. 4: Regional onsets of land-use categories and decline of foraging. A) Onsets represent the earliest time step assessed at the "common" prevalence level (1-20\% land area) for extensive agriculture, intensive agriculture, and pastoralism; the earliest time step assessed as "present" for urbanism. B) Decline represents the latest time step assessed at the "common" prevalence level for foraging.

The current dataset draws attention to the prevalence of agricultural economies across the globe (Fig. 4A), rather than focusing on centers of initial domestication, of which there are now at least 11 worldwide (28). At 10,000 BP these centers were limited to minimal or common components in parts of Southwest Asia. Subsequently, agriculture became much more widespread both through secondary dispersal, from Southwest Asia and eastern China, as well as through new domestications in the Americas, New Guinea, and Africa. By 6,000 BP, 42\% of land units had at least minimal extensive agriculture (swidden/shifting cultivation and other forms of non-continuous cultivation) and it was common in over $14 \%$ of units. Intensive agriculture (all forms of continuous cultivation) was geographically constricted (the Mediterranean, Southwest Asia, South Asia, and eastern China) and common in only a few regions (12 at 6,000 BP) of 
suitable climatic conditions until 4000-3000 BP, only spreading more broadly after $2000 \mathrm{BP}$ (65 regions with at least common intensive agriculture at 2,000 BP).

This study also illuminates the relationships between different modes of land use. Pastoralism was connected to agricultural centers of origin in Southwest Asia, East Asia, and the Andes, suggesting a close relationship between both types of production. By 10,000 BP, both agriculture and pastoralism were established in the earliest source regions with a focus first around Southwest Asia and the Mediterranean, but by 8,000 BP pastoralism had spread farther from Southwest Asia, perhaps due to the proximity of this region to arid environments where herding was more productive than farming (Fig. 4A). In the Americas, pastoralism was restricted to its origin in the Andes (present from 8,000 BP) until after $1500 \mathrm{CE}$ with the introduction of western domesticates.

After 6,000 BP, the geographic spread of extensive agriculture shows a markedly different pattern than that of pastoralism, due to its dispersal from additional source locations in East Asia and the Americas. Over the same time period, pastoralism spread across northern Africa and central Asia and was common or widespread across much of Eurasia and Africa by 4,000 BP, including many regions where neither form of agriculture was common until between 4,000-3,000 BP. Not until 3,000 BP was extensive agriculture (75 regions) practiced commonly at a greater geographic scale than pastoralism (64 regions). Patterns of regional land use demonstrate the importance of pastoralist production across arid regions (Fig. 4A), including arid and northern regions where agriculture was unsuitable, and document that the type of management practiced on western Eurasian herd animals was highly adaptable and transferable.

\section{Early onset of intensive land use: assessments vs. models}

Regional onsets of intensive agriculture, described by archaeologists, were generally earlier than estimates of cultivated crop areas derived from the most commonly used, spatially explicit, global reconstruction of land-use history (the HYDE dataset (14)). ArchaeoGLOBE findings complement previous regional (e.g., Europe) land-cover studies based on palaeoecological data $(36,37)$. Of the 130 ArchaeoGLOBE regions currently making up Earth's agricultural regions (regions with $>1 \%$ crop area in HYDE at $2000 \mathrm{CE}$ ), 69 archaeological onsets were earlier when assessed at the "common" level, in regions encompassing 54\% of global crop area at $2000 \mathrm{CE}$ (Fig. 5C), and $>67$ were earlier at the "widespread" level (56\% of global crop area at $2000 \mathrm{CE}$; Fig. 5D). Although 26 archaeological onsets at the common level were later than HYDE, including 13 regions later by $>1,000$ years $(8.4 \%$ of global crop area at $2000 \mathrm{CE})$, ArchaeoGLOBE onsets were $>1000$ years earlier in 27 regions encompassing $21.8 \%$ of global crop area in 2000. At the widespread level, archaeological onsets were later by $<=250$ years in just 3 regions ( $5 \%$ of 2000 global crop area), and earlier by $>1000$ years in 21 regions accounting for $22.0 \%$ of global crop area in 2000 . In contrast, a comparison with KK10, a less commonly applied historical land-cover change reconstruction, known for representing early agricultural transformation of land, showed generally earlier onsets of intensive land use than ArchaeoGLOBE (Fig. S7; (15)). 
A

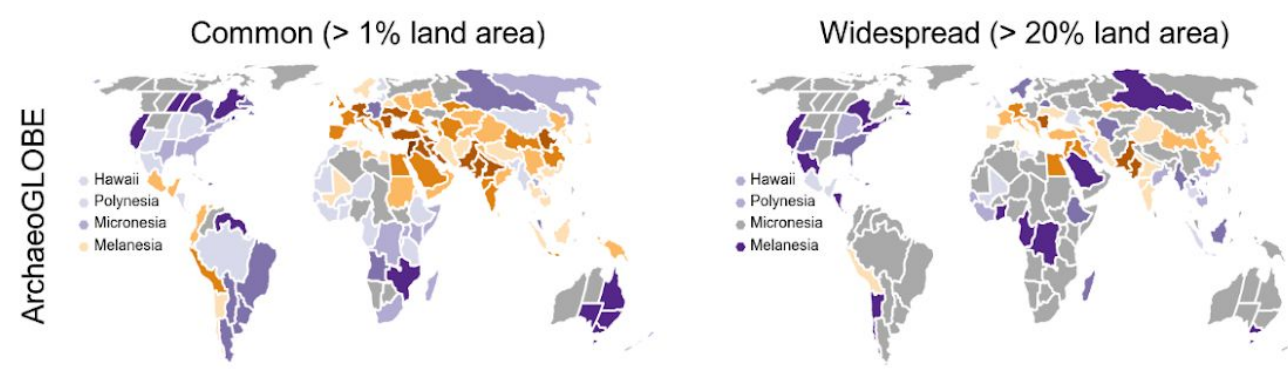

B
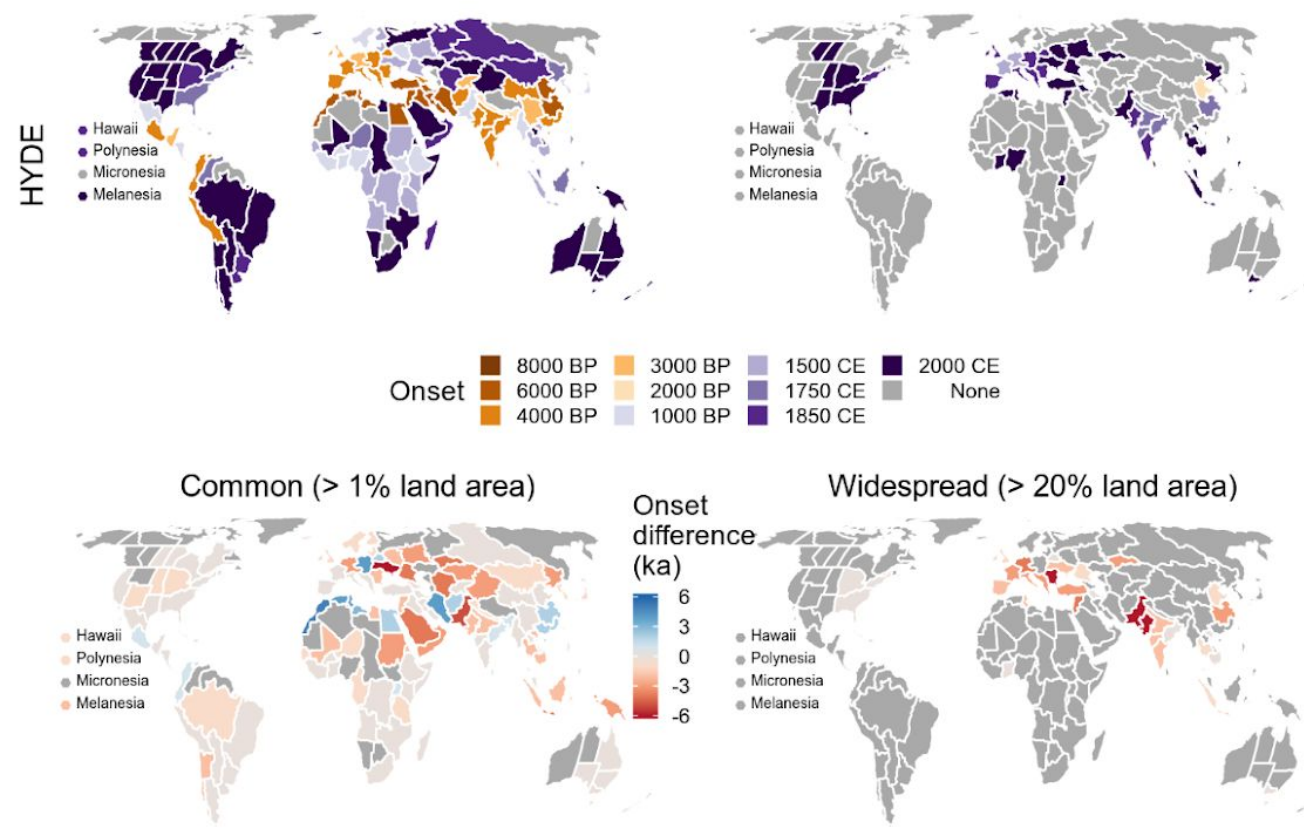

C

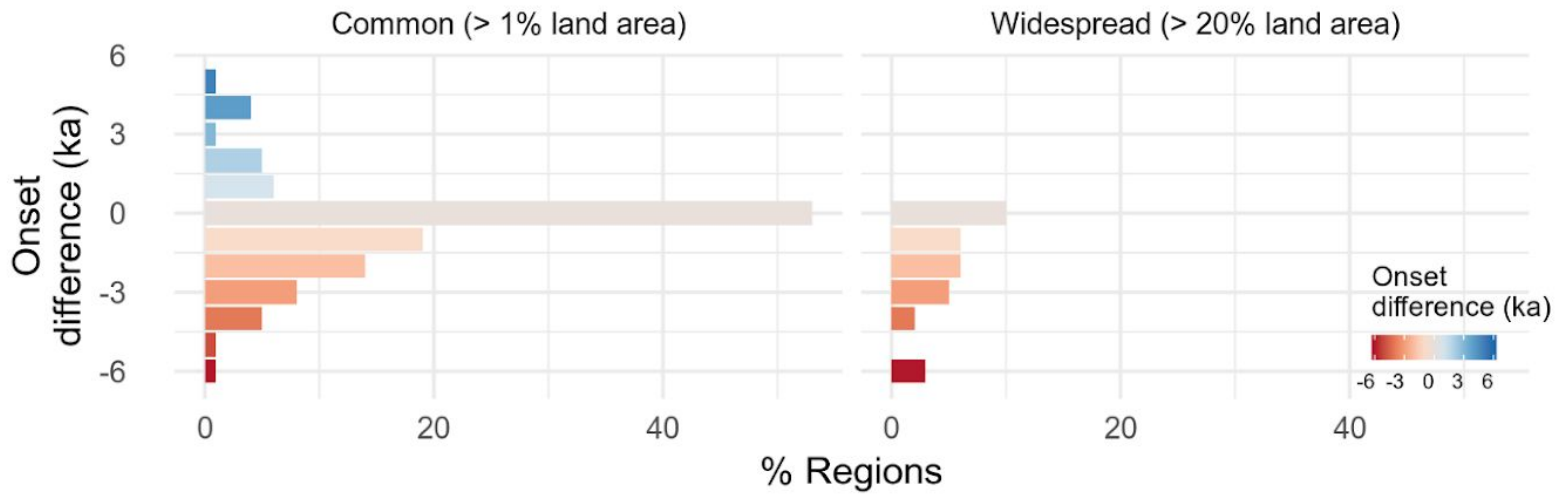

Fig. 5: Comparisons of agricultural onset in ArchaeoGLOBE versus HYDE. A) Onset of intensive agriculture covering $>=1 \%$ regional area (common level) and $>=20 \%$ regional area (widespread level) in both ArchaeoGLOBE and HYDE datasets; regions colored in grey did not surpass the associated threshold by 1850CE for ArchaeoGLOBE and 2000CE for HYDE. B) Map of differences in onset of intensive agriculture at common and widespread levels, in thousands of years; negative numbers highlight earlier ArchaeoGLOBE estimates). C) 
Distributions of onset timing differences at common and widespread levels, same data and scale as B.

\section{Discussion}

The ArchaeoGLOBE dataset highlights broad patterns and consistencies in archaeological data while also identifying exceptions and knowledge gaps. Our data show geographical variability in total number of respondents, expertise level, and data quality, suggesting that the breadth of archaeological knowledge differs greatly from one region to another. Potential causes of geographical inconsistencies in archaeological knowledge include the varying conditions under which archaeologists work, the cumulative legacy and positive feedback of early research interests, and the physical accessibility (both real and perceived) of archaeological sites (see also (38)). Although we made rigorous efforts to recruit archaeological knowledge contributions as widely as possible, biases in the dataset also derive from the anglophone orientation of key project investigators, as well as the limitations of their professional networks. These biases exacerbate historical geographical biases in the pursuit and construction of archaeological knowledge, including the application of environmental archaeological methods. ArchaeoGLOBE respondents may not form a representative sample of global archaeologists, but it is still clear that several regions have seen more intensive archaeological research. Regional hotspots of intensive study are concentrated heavily in Europe, Southwest Asia, and portions of the Americas; a pattern also observed for ecological field sites (39) and UNESCO World Heritage sites (40).

Regional cold spots that have received much less attention concentrate in Southeast Asia, and Central and West Africa where resources available for archaeological fieldwork and training are limited. Nonetheless, experts in these regions were able to contribute generalized accounts of land-use trajectories. For instance, archaeobotanical investigations of the cultivation and domestication of indigenous cereals in Sub-Saharan Africa (41-43) are beginning to shed light on earlier and more extensive forms of agriculture. Similar less-investigated indigenous agricultural practices likely characterize parts of Southeast Asia and northern India during the mid-Holocene (e.g., (44-46)). Hence, the ArchaeoGLOBE project can help archaeologists prioritize future collection of empirical data and local capacity building to improve the reliability of global perspectives.

\section{Deepening the Anthropocene}

Archaeologists and anthropologists have broadly defined "domestication" and to a lesser extent "agriculture" (e.g., (28)). However, "hunting and gathering" is a more varied and complex subsistence adaptation than originally conceptualized. Its definition generates debate among scholars by blurring countless variances in land use, resource management, and anthropogenic environmental change. Foraging, or "foraging/hunting/gathering/fishing," was used here to describe subsistence economies and land-use practices that generally exhibit lower amounts of direct human alteration of ecosystems and control of plant and animal life cycles (see (47)).

Within this broad category are many forms of resource procurement and land management that have drastically changed landscapes, and we now recognize that foragers may have initiated 
dramatic and sometimes irreversible environmental change (e.g., (48)). In addition to altering biotic communities around the world through transport and propagation of favored species, extensive early land use by hunter-gatherers may also indicate widespread use of fire to enhance success in hunting and foraging (49). Systematic burning has implications for the global carbon cycle through increased greenhouse gas emissions, for water-cycles through changes in vegetation and evapotranspiration, and for temperatures through changes in albedo $(50,51)$.

Globally widespread evidence of hunter-gatherer land use indicates that ecological conditions across most of the terrestrial biosphere were influenced significantly by human activities, even before the domestication of plants and animals. While our dichotomous parsing of hunter-gatherers and agriculturalists is primarily operational, such divisions are still useful. Our data seem to support a unilineal trajectory towards increasingly intensive land use and the replacement of foraging with pastoralism and agriculture, a process that appears largely irreversible over the long term. Such trends also mask more complex pathways, as well as reversals, at the local scale in numerous regions. In some parts of the world agriculture did not simply replace foraging, but merged with it and ran in parallel for some time, either as a patchwork of different peoples or seasonal shifts. The environmental effects of such mixed-mode land use are difficult to see in the archaeological/palaeoecological record, and perhaps often missed in the dichotomous view of replacement by more advanced systems. Through time, as land became increasingly densely occupied and land use more intensive, opportunities for flexibility in subsistence strategies and the resilience this supported were reduced.

This global archaeological assessment of early land use reveals a much earlier and more widespread global onset of intensive agriculture than the spatially-explicit global historical reconstruction most commonly used to inform modelling studies of pre-industrial vegetation and climate change (HYDE; (14)). However, archaeological onsets of intensive agriculture appeared slightly later than in the less widely used KK10 reconstruction (15). Substantial methodological differences and uncertainties between archaeological estimates and historical reconstructions mean that comparisons among ArchaeoGLOBE, HYDE, and KK10 must be treated with caution (52). The regional land-use estimates of our study represent a first step towards more accurate, empirically grounded, spatially-explicit global reconstructions of long-term changes in land use and provide reference points and procedural approaches to constrain and correct these biases in future work. Our hope is that our global archaeological assessment, and the collaborative approach it represents, will help stimulate and support future efforts, such as work currently in progress through the PAGES LandCover6k initiative $(18,25)$, towards the common goal of understanding early land use as a driver of long-term global environmental changes across the Earth system, including changes in climate.

\section{References and Notes:}

1. B. D. Smith, M. A. Zeder, The onset of the Anthropocene. Anthropocene. 4, 8-13 (2013).

2. P. V. Kirch, Archaeology and global change: The Holocene record. Annu. Rev. Environ. Resour. 30, 409-440 (2005). 
3. W. F. Ruddiman, E. C. Ellis, J. O. Kaplan, D. Q. Fuller, Defining the epoch we live in. Science. 348, 38-39 (2015).

4. N. L. Boivin et al., Ecological consequences of human niche construction: Examining long-term anthropogenic shaping of global species distributions. Proc. Natl. Acad. Sci. U. S. A. 113, 6388-6396 (2016).

5. J. O. Kaplan et al., Holocene carbon emissions as a result of anthropogenic land cover change. Holocene. 21, 775-791 (2011).

6. D. Q. Fuller et al., The contribution of rice agriculture and livestock pastoralism to prehistoric methane levels: An archaeological assessment. Holocene. 21, 743-759 (2011).

7. E. C. Ellis, M. Maslin, N. Boivin, A. Bauer, Involve social scientists in defining the Anthropocene. Nature News. 540, 192 (2016).

8. E. C. Ellis et al., Used planet: a global history. Proc. Natl. Acad. Sci. U. S. A. 110, 7978-7985 (2013).

9. D. M. J. S. Bowman et al., The human dimension of fire regimes on Earth. J. Biogeogr. 38, 2223-2236 (2011).

10. W. F. Ruddiman et al., Late Holocene climate: Natural or anthropogenic? Rev. Geophys. 54, 93-118 (2016).

11. E. C. Ellis, Anthropogenic transformation of the terrestrial biosphere. Philos. Trans. A Math. Phys. Eng. Sci. 369, 1010-1035 (2011).

12. P. Roberts, C. Hunt, M. Arroyo-Kalin, D. Evans, N. Boivin, The deep human prehistory of global tropical forests and its relevance for modern conservation. Nat Plants. 3, 17093 (2017).

13. F. Marshall et al., Ancient herders enriched and restructured African grasslands. Nature (2018), doi:10.1038/s41586-018-0456-9.

14. K. K. Goldewijk, A. Beusen, J. Doelman, E. Stehfest, Anthropogenic land use estimates for the Holocene--HYDE 3.2. Earth System Science Data. 9, 927-953 (2017).

15. J. O. Kaplan, K. M. Krumhardt, The KK10 Anthropogenic land cover change scenario for the preindustrial Holocene, link to data in NetCDF format, supplement to: Kaplan, J. O; Krumhardt, K.M; Ellis, E. C; Ruddiman, W. F; Lemmen, C; Klein Goldewijk, K. (2011): Holocene carbon emissions as a result of anthropogenic land cover change. The Holocene, 21(5), 775-791 (2011), , doi:10.1594/PANGAEA.871369.

16. M.-J. Gaillard et al., Holocene land-cover reconstructions for studies on land cover-climate feedbacks. Clim. Past. 6, 483-499 (2010).

17. K. K. Goldewijk, M.-J. Gaillard, K. Morrison, M. Madella, N. Whitehouse, Uncovering the past: Multidisciplinary research on historic land cover and land use. PAGES Mag. 24, 81-81 (2016).

18. M.-J. Gaillard, K. Morrison, M. Madella, N. Whitehouse, Past land-use and land-cover change: the 
challenge of quantification at the subcontinental to global scales. PAGES Mag. 26, 3-3 (2018).

19. C. N. H. McMichael, F. Matthews-Bird, W. Farfan-Rios, K. J. Feeley, Ancient human disturbances may be skewing our understanding of Amazonian forests. Proc. Natl. Acad. Sci. U. S. A. 114, 522-527 (2017).

20. A. Dawson et al., Finding the magnitude of human-induced Northern Hemisphere land-cover transformation between 6 and 0.2 ka BP. PAGES Mag. 26, 34-35 (2018).

21. J. W. Williams, P. Tarasov, S. Brewer, M. Notaro, Late Quaternary variations in tree cover at the northern forest-tundra ecotone. Journal of Geophysical Research: Biogeosciences. 116 (2011) (available at https://onlinelibrary.wiley.com/doi/pdf/10.1029/2010JG001458).

22. B. Pirzamanbein et al., Creating spatially continuous maps of past land cover from point estimates: A new statistical approach applied to pollen data. Ecol. Complex. 20, 127-141 (2014).

23. A.-K. Trondman et al., Pollen-based quantitative reconstructions of Holocene regional vegetation cover (plant-functional types and land-cover types) in Europe suitable for climate modelling. Glob. Chang. Biol. 21, 676-697 (2015).

24. M. Zanon, B. A. S. Davis, L. Marquer, S. Brewer, J. O. Kaplan, European forest cover during the past 12,000 years: A palynological reconstruction based on modern analogs and remote sensing. Front. Plant Sci. 9, 253 (2018).

25. LandCover6k Land-Use Group Members et al., Global-scale comparisons of human land use: developing shared terminology for land-use practices for global change. PAGES Mag. 26, 8-9 (2018).

26. T. A. Kohler, P. I. Buckland, K. W. Kintigh, R. K. Bocinsky, J. Terstriep, Paleodata for and from archaeology. PAGES Mag. 26, 68-69 (2018).

27. J. W. Lewthwaite, A. Sherratt, Chronological atlas. Cambridge Encyclopedia of Archeology, Cambridge Univ. Press, Cambridge (1980).

28. G. Larson et al., Current perspectives and the future of domestication studies. Proc. Natl. Acad. Sci. U.S. A. 111, 6139-6146 (2014).

29. J. M. Erlandson, T. J. Braje, Archeology and the Anthropocene. Anthropocene. 4, 1-7 (2013).

30. K. W. Kintigh et al., Grand challenges for archaeology. Proc. Natl. Acad. Sci. U. S. A. 111, 879-880 (2014).

31. B. S. Arbuckle et al., Data sharing reveals complexity in the westward spread of domestic animals across Neolithic Turkey. PLoS One. 9, e99845 (2014).

32. S. S. Downey, W. R. Haas Jr, S. J. Shennan, European Neolithic societies showed early warning signals of population collapse. Proc. Natl. Acad. Sci. U. S. A. 113, 9751-9756 (2016).

33. K. W. Kintigh et al., Cultural dynamics, deep time, and data: Planning cyberinfrastructure investments for archaeology. Advances in Archaeological Practice. 3, 1-15 (2015). 
34. Materials and methods are available as supplementary materials at the Science website.

35. S. Bartling, S. Friesike, Eds., Opening science: The evolving guide on how the internet is changing research, collaboration and scholarly publishing (Springer, Cham, 2014).

36. A. Bevan et al., The changing face of the Mediterranean - Land cover, demography and environmental change: Introduction and overview. The Holocene. 29, 703-707 (2019).

37. N. Roberts et al., Europe's lost forests: a pollen-based synthesis for the last 11,000 years. Sci. Rep. 8, 716 (2018).

38. T. A. Surovell et al., The end of archaeological discovery. Am. Antiq. 82, 288-300 (2017).

39. L. J. Martin, B. Blossey, E. Ellis, Mapping where ecologists work: biases in the global distribution of terrestrial ecological observations. Front. Ecol. Environ. 10, 195-201 (2012).

40. B. S. Frey, P. Pamini, L. Steiner, Explaining the World Heritage List: an empirical study. Int. Rev. Law Econ. 60, 1-19 (2013).

41. K. Manning, R. Pelling, T. Higham, J.-L. Schwenniger, D. Q. Fuller, 4500-Year old domesticated pearl millet (Pennisetum glaucum) from the Tilemsi Valley, Mali: new insights into an alternative cereal domestication pathway. J. Archaeol. Sci. 38, 312-322 (2011).

42. F. Winchell, C. J. Stevens, C. Murphy, L. Champion, D. Fuller, Evidence for sorghum domestication in fourth millennium BC eastern Sudan: Spikelet morphology from ceramic impressions of the Butana Group. Curr. Anthropol. 58, 673-683 (2017).

43. A. U. Kay et al., Diversification, intensification and specialization: Changing land use in western Africa from $1800 \mathrm{BC}$ to AD 1500. Journal of World Prehistory. 32, 179-228 (2019).

44. T. Denham, Early farming in Island Southeast Asia: an alternative hypothesis. Antiquity. 87, 250-257 (2013).

45. C. O. Hunt, R. J. Rabett, Holocene landscape intervention and plant food production strategies in island and mainland Southeast Asia. J. Archaeol. Sci. 51, 22-33 (2014).

46. D. Q. Fuller, C. Murphy, Overlooked but not forgotten: India as a center for agricultural domestication. General Anthropology. 21, 1-8 (2014).

47. D. Rindos et al., Symbiosis, instability, and the origins and spread of agriculture: A new model [and comments and reply]. Curr. Anthropol. 21, 751-772 (1980).

48. R. Hames, The Ecologically Noble Savage debate. Annu. Rev. Anthropol. 36, 177-190 (2007).

49. D. M. J. S. Bowman et al., Fire in the Earth system. Science. 324, 481-484 (2009).

50. M. Pfeiffer, A. Spessa, J. O. Kaplan, A model for global biomass burning in preindustrial time: LPJ-LMfire (v1. 0). Geoscientific Model Development. 6, 643-685 (2013).

51. N. Nakicenovic et al., Emissions scenarios. Special report of the Intergovernmental panel on climate change (2000), (available at https://www.osti.gov/etdeweb/biblio/20134132). 
52. J. Kaplan et al., Constraining the deforestation history of Europe: Evaluation of historical land use scenarios with pollen-based land cover reconstructions. Land. 6, 91 (2017).

53. M. Kynn, The "heuristics and biases" bias in expert elicitation. J. R. Stat. Soc. Ser. A Stat. Soc. 171, 239-264 (2008).

54. S. N. Wood, Generalized additive models: An introduction with $R$ (Chapman and Hall/CRC, 2017).

55. E. J. Pedersen, D. L. Miller, G. L. Simpson, N. Ross, Hierarchical generalized additive models: An introduction with mgcv (e27320v1, PeerJ Preprints, 2018), , doi:10.7287/peerj.preprints.27320v1.

56. M. Szumilas, Explaining odds ratios. J. Can. Acad. Child Adolesc. Psychiatry. 19, 227-229 (2010).

57. B. Marwick, Computational reproducibility in archaeological research: Basic principles and a case study of their implementation. Journal of Archaeological Method and Theory. 24, 424-450 (2017).

Acknowledgments: Funding: This material is based upon work supported by the National Science Foundation under Grant CNS 115210 awarded to E.C. Ellis in 2011. Author contributions: a complete list of contributions to the paper is contained in the Full Author List in a separate file. Competing interests: authors declare no competing interests. Data and materials availability: all project data are in the public domain (CC-0) and available online on the project's Dataverse page (https://dataverse.harvard.edu/dataverse/ArchaeoGLOBE, specifically https://doi.org/10.7910/DVN/CNCANQ, https://doi.org/10.7910/DVN/CQWUBI). We include the entire R code used for all the analysis and visualizations contained in this paper in our repository at

https://doi.org/10.7910/DVN/6ZXAGT

Supplementary Materials:

Materials and Methods

Figures S1-S7

Tables S1-S4

References (53-57) 